\title{
Systemic Immune Response after Rectocolonic Administration of Ovalbumin in Mice
}

\author{
Edouard Louis ${ }^{\mathrm{a}, *}$ Denis Franchimont ${ }^{\mathrm{a}}$ Annouk Lamproye ${ }^{\mathrm{a}}$ Catherine van Kemseke ${ }^{\mathrm{a}}$ Nicole Schaaf ${ }^{\mathrm{b}}$ Philippe \\ Mahieu ${ }^{\mathrm{b}}$ Jacques Belaiche ${ }^{\mathrm{a}}$ \\ Departments of ${ }^{a}$ Gastroenterology and ${ }^{b}$ Immunology, CHU of Liège, Belgium
}

\begin{abstract}
The aim of our study was to determine the effect of a rectocolonic preimmunization with ovalbumin on the systemic immune response induced by a subsequent subcutaneous injection of this antigen in Balb/c mice. One rectocolonic, but not intragastric, administration of $25 \mathrm{mg}$ of ovalbumin induced a detectable increase in serum anti-ovalbumin antibody level. The level reached was however much lower than after subcutaneous injection. Both intragastric and rectocolonic immunization with ovalbumin induced specific systemic cellular tolerance. However, after rectocolonic, but not intragastric, preimmunization there was no systemic humoral tolerance to this antigen. These differences in systemic immune responses after rectocolonic or intragastric administration of ovalbumin could be due to different stimulation of the systemic immune system or to differences between the colonic and small bowel mucosal immune system, which remain to be elucidated.
\end{abstract}

Keywords : Immune tolerance ; Immunization ; Colon ; Rectum

\section{Introduction}

Functional immunology of the gastrointestinal tract has almost exclusively been studied by oral (or intragastric) administration of antigens [1]. Other means of antigen administration have rarely been studied. However, soluble antigens are largely degraded in the lumen of the digestive tract before immune presentation in the digestive mucosa, and small amounts are absorbed as intact antigen [1]. Moreover, this absorption occurs almost exclusively in the small intestine and not in the colon or rectum. Therefore, immune response after oral immunization is not necessarily a representation of the gastrointestinal tract as a whole.

Immune response after rectocolonic administration of antigens has rarely been studied [2-5]. Particularly, the effect of a rectocolonic preimmunization on the subsequent systemic immune response has never been studied. This route of administration leads to a presentation of the antigen to the colonic and rectal mucosa. Degradation of the soluble antigen by proteolytic enzymes does not occur. It thus achieves a different stimulation of the mucosal immune system than by oral administration of the antigen.

The aim of our study was to test the effect of a rectocolonic administration of ovalbumin on the systemic immune response induced by a subsequent subcutaneous administration of this antigen.

\section{Materials and Methods}

Animals. Male Balb/c mice (4-8 weeks old) were obtained from the Iffa Credo Laboratories in Brussels, Belgium.

Antigen. Crystallized and lyophilized ovalbumin grade V was obtained from Sigma, St. Louis, Mo., USA.

Study Design. The study was divided into two parts: first, the humoral response after rectocolonic immunization and secondly the effect of rectocolonic preimmunization on the subsequent response to the same antigen administered subcutaneously. Five mice were used for each experimental condition.

\footnotetext{
${ }^{*}$ E. L. is supported by SmithKline Beecham Biologicals and the National Funds for Scientific Research of Belgium.
} 
Systemic humoral immune response after rectocolonic immunization - comparison with intragastric and subcutaneous immunization: systemic humoral immune response was evaluated by serum anti-ovalbumin antibody levels. Mice were divided into four groups: nonimmunized mice as negative controls, rectocolonic immunization with $25 \mathrm{mg}$ ovalbumin in $0.7 \mathrm{ml}$ saline, intragastric immunization with $25 \mathrm{mg}$ ovalbumin in $0.2 \mathrm{ml}$ saline and subcutaneous immunization with $100 \mu \mathrm{g}$ ovalbumin precipitated in $\mathrm{Al}(\mathrm{OH})_{3}$. They were immunized on day 0 and killed on day $0,4,8,12,16,20$ or 24 .

\section{Effect of rectocolonic preimmunization with ovalbumin on the subsequent systemic humoral and cellular response to this antigen administered subcutaneously - comparison with intragastric preimmunization: mice were divided into four groups: positive controls (subcutaneous immunization without preimmunization), negative controls (neither preimmunization nor immunization), rectocolonic preimmunization ( $25 \mathrm{mg}$ ovalbumin in $0.7 \mathrm{ml}$ saline) and intragastric preimmunization ( $25 \mathrm{mg}$ ovalbumin in $0.2 \mathrm{ml}$ saline). They were preimmunized on day 0 , immunized subcutaneously on day 20 and killed for immune evaluation on day 30 .}

Humoral response was evaluated by the serum anti-ovalbumin antibody level and cellular response by the proliferation rate of inguinal (draining nodes of the tail) lymph node cells cultured with ovalbumin.

Immunization Procedures. For intragastric immunization, ovalbumin was diluted in saline to $125 \mathrm{mg} / \mathrm{ml}$ and 0.2 $\mathrm{ml}$ was given intra-gastrically by a small catheter under light ether anesthesia. For subcutaneous immunization, ovalbumin was precipitated in $\mathrm{Al}(\mathrm{OH})_{3}$ at $2 \mathrm{mg} / \mathrm{ml}$. Fifty microliters of this suspension were injected subcutaneously at the base of the tail with a 30 -gauge needle. For rectocolonic immunization, ovalbumin was diluted in saline to $35.7 \mathrm{mg} / \mathrm{ml}$ and $0.7 \mathrm{ml}$ were slowly injected at constant pressure through the anus with an 1$\mathrm{cm}$-long 24-gauge catheter under light ether anesthesia.

Immune Evaluation. Antibody assay was performed on the sera. Mice were killed by cervical dislocation and bled by cardiac puncture. 50-200 $\mu$ l of serum were obtained from each mouse and stored at $-20^{\circ} \mathrm{C}$. Serum antiovalbumin total immunoglobulin, IgG, IgA and IgM were measured by ELISA. Microtitre plates were coated with $100 \mu \mathrm{l}$ of an ovalbumin solution $(100 \mu \mathrm{g} / \mathrm{ml})$ per well at $4{ }^{\circ} \mathrm{C}$ for $24 \mathrm{~h}$. Plates were rinsed 3 times with a washing solution (PBS $+0.5 \%$ Tween). Plates were then incubated for $1 \mathrm{~h}$ at room temperature with a bovine powdered milk solution (PBS $+0.5 \%$ Tween $+1 \%$ powdered milk) to block nonspecific sites. On each plate, wells were left without ovalbumin (blanks). Plates were rinsed 3 times with the washing solution. Sera diluted to $1 / 10,1 / 40,1 / 60$ and $1 / 640$ were added $\left(50 \mu \mathrm{l} /\right.$ well) for $1 \mathrm{~h}$ at $37^{\circ} \mathrm{C}$. Reference serum was obtained by serum pooling from mice immunized several times subcutaneously with ovalbumin; it was diluted to $1 / 500,1 / 2,000$, $1 / 8,000$ and $1 / 32,000$. Plates were rinsed 3 times with the washing solution. Total immunoglobulins were detected with peroxidase-conjugated goat anti-mouse immunoglobulin (Dako) used at 1/500. IgA, $\operatorname{IgM}$ and $\operatorname{IgG}$ were detected with peroxidase-conjugated goat anti-mouse $\operatorname{IgA}$, IgM or IgG used at $1 / 500$. Plates were incubated for $1 \mathrm{~h}$ at $37^{\circ} \mathrm{C}$ and rinsed 3 times with the washing solution. The reaction was developed with

$O$-phenylenediamine dihydrochloride for $5 \mathrm{~min}\left(50 \mu \mathrm{l} /\right.$ well). The reaction was stopped with $\mathrm{H}_{2} \mathrm{SO}_{4}(25 \mu \mathrm{l} / \mathrm{well})$. Plates were read with a spectrophotometer type LP 200 on $405 \mathrm{~nm}$. Provided that a correct dilution effect was observed for each serum and the blanks had an optic density lower than 0.1 at $1 / 640$ and 0.3 at $1 / 10$, the final result was expressed as the ratio between the optic density of the serum tested diluted to $1 / 640$ (after subcutaneous immunization) or 1/10 (after oral or anal immunization) and the reference serum on the same plate diluted to $1 / 8000$. The use of this reference serum on each plate allowed highly reproducible results. Antigeninduced T cell proliferation: inguinal lymph nodes (draining lymph nodes of the tail) were used as a source of cells for antigen-induced proliferation. 400,000 cells were cultured in flat bottom microwell plates in $0.2 \mathrm{ml}$ of culture medium (RPMI 1640 Gibco $+10 \%$ decomplemented fetal calf serum $+1 \%$ nonessential amino acids + $1 \%$ sodium pyruvate + penicillin and streptomycin $+0.1 \%$ mercaptoethanol). Cells were cultured in culture medium alone or with ovalbumin $100 \mu \mathrm{g} / \mathrm{well}$. Moreover, a control of the nonspecific mitogenic activity was made for each condition using pokeweed mitogen $(1 \%)$. Cultures were triplicated for each condition. The plates were incubated in a humidified $5 \% \mathrm{CO}_{2}, 95 \%$ air atmosphere for $72 \mathrm{~h}$ and were pulsed with $1 \mu \mathrm{Ci}$ (in $10 \mu \mathrm{l}$ ) of ${ }^{3} \mathrm{H}$-thymidine for the final $24 \mathrm{~h}$ of culture. Cultures were harvested with an automated sample harvester and radioactive measurement was determined in a Packard liquid scintillation analyzer. The final result is the ratio between the mean proliferation expressed in counts per minute of the culture with ovalbumin and the mean proliferation in counts per minute of the culture without ovalbumin for each condition.

Statistical Analysis. Results are expressed as means \pm SEM of the results obtained with the 5 mice used for each experimental condition. Comparisons of means were made using a two-tailed t test. 


\section{Results}

Systemic Humoral Immune Response after Rectocolonic Immunization: Comparison with Intragastric and Subcutaneous Immunization

The anti-ovalbumin antibody serum levels after one rectocolonic or intragastric immunization are shown in figure 1. There was no detectable level after intragastric immunization and a small increasing quantity after rectocolonic immunization. Sixteen days after immunization, the antibody levels in the sera diluted to $1 / 10$ were $0.89 \pm 0.13$ and $0.4 \pm 0.03$ for the rectocolonic and the intragastric immunizations, respectively. The level after rectocolonic immunization, but not after intragastric immunization, was significantly higher than the negative control $(0.29 \pm 0.04 ; p=0.0028)$. This level was however much lower than the antibody level 16 days after subcutaneous immunization. This was also significantly higher than the negative control $(1.04 \pm 0.07 \mathrm{vs} .0 .085 \pm$ 0.004 in sera diluted to $1 / 640 ; \mathrm{p}=0.0001$ ) and reached an optical density (OD) comparable to the one obtained after rectocolonic immunization, but with a serum 64-fold more dilute. The analysis of the antibody subclasses showed that after both rectocolonic and subcutaneous immunizations, there was more IgG and $\operatorname{IgM}$ but very little IgA.

\section{Effect of Rectocolonic Preimmunization on a Subsequent Subcutaneous Immunization}

The results of the effect on systemic humoral response are shown in figure 2 . There was a significant decrease in the anti-ovalbumin antibody level induced by a subcutaneous immunization after the intragastric preimmunization. On the other hand we did not find any significant decrease after the rectocolonic preimmunization. The effect on systemic cellular response is shown in figure 3 . There was a significant decrease in the inguinal lymph node cell proliferation rate induced by a subcutaneous immunization after both intragastric and rectocolonic preimmunization. This decrease was specific because the mitogenic activity elicited by $1 \%$ pokeweed mitogen was unchanged.

Fig. 1. Serum-anti-ovalbumin antibody level evolution after rectocolonic ( $\Delta$ ) or intragastric ( $\square$ ) immunization with ovalbumin and in negative controls (nonimmunized; $O$ ). The results shown are expressed as means $\pm S E M$ of the ratios between the $O D$ of the serum tested and the $O D$ of the reference serum on the same plate. Five mice were used for each condition. Anti-ovalbumin antibody levels induced by rectocolonic or intragastric immunization were compared to level in negative control $\left({ }^{*} p<0.01 ; * * p<0.001\right)$.

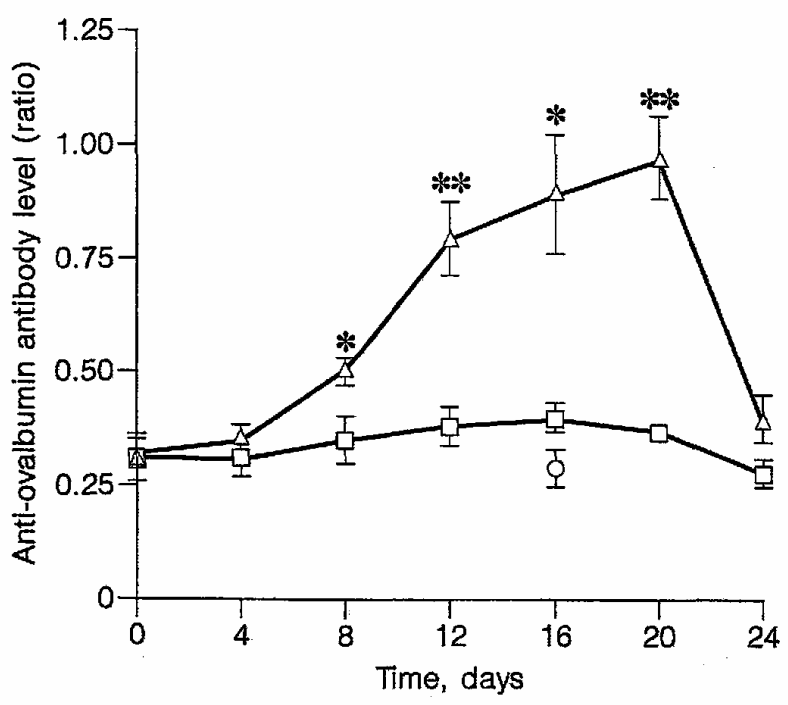


Fig. 2. Serum anti-ovalbumin antibody levels 10 days after a subcutaneous immunization with $100 \mu \mathrm{g}$ of ovalbumin precipitated in $\mathrm{Al}(\mathrm{OH})_{3}$ in mice not preimmunized, in negative controls (no immunization nor preimmunization), and in mice preimmunized by the intragastric or the rectocolonic route 20 days before immunization. The results shown are expressed as means \pm SEM of the ratios between the OD of the serum tested and the $O D$ of the reference serum on the same plate. Five mice were used for each condition. Intragastric and rectocolonic preimmunization were compared with no preimmunization $\left({ }^{*} p<0.02\right)$.

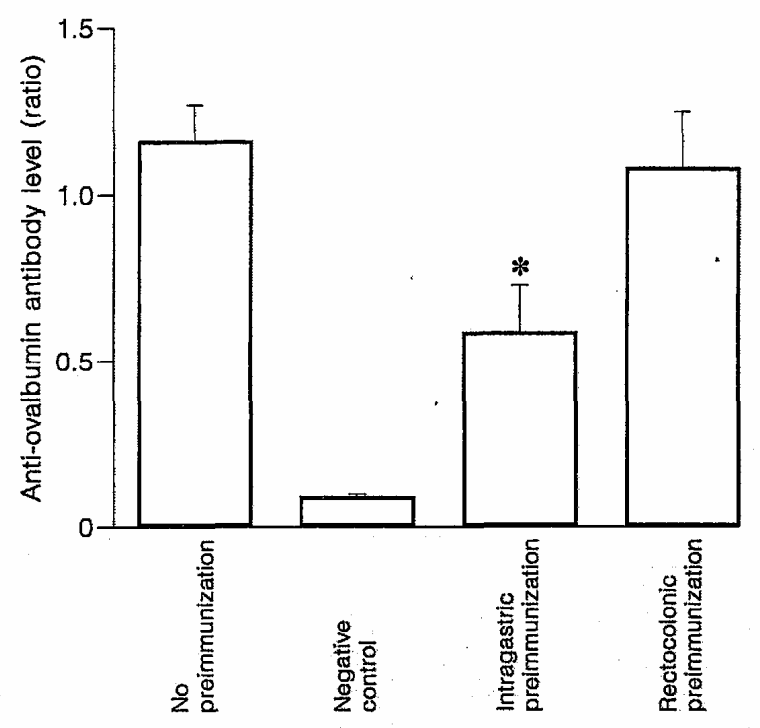

Fig. 3. Proliferation rate of inguinal lymph node lymphocytes induced by ovalbumin in vitro 10 days after a subcutaneous immunization with $100 \mu \mathrm{g}$ of ovalbumin precipitated in $\mathrm{Al}(\mathrm{OH})_{3}$, in mice not preimmunized, in negative controls (no immunization nor preimmunization) and in mice preimmunized by the intragastric or the rectocolonic route 20 days before immunization. The results shown are expressed as means \pm SEM of the ratios between culture with and without ovalbumin (stimulation indices; SI). Five mice were used for each condition. Intragastric and rectocolonic preimmunization were compared with no preimmunization $(* p<0.003)$.

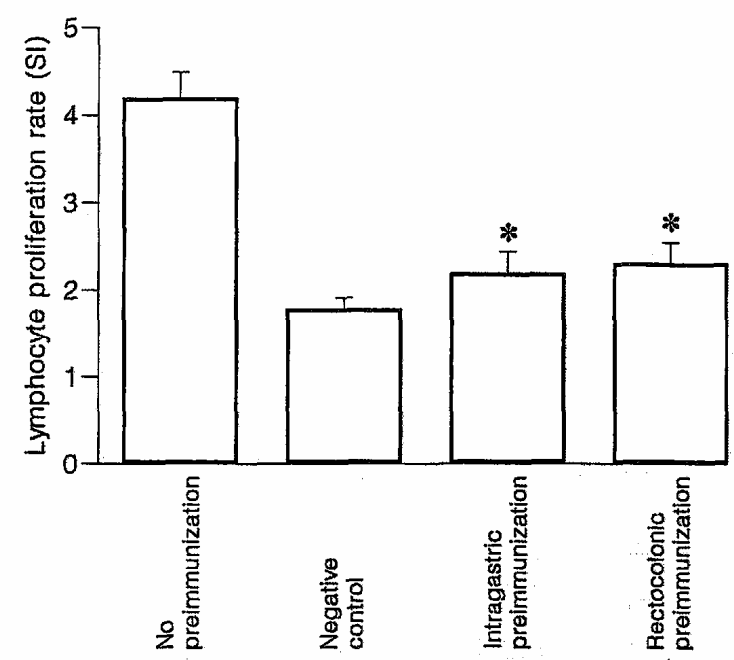




\section{Discussion}

Our results confirm previous studies on oral immunization in mice: a single oral or intragastric administration of $25 \mathrm{mg}$ of ovalbumin gives rise to a low or undetectable serum anti-ovalbumin antibody level but leads to both humoral and cellular tolerance to this antigen [1].

We particularly studied the rectocolonic route of immunization. This immunization led to a detectable serum level of anti-ovalbumin antibody and induced a cellular but not a humoral tolerance to ovalbumin.

The are few studies on the systemic immune response after administration of an antigen by the rectocolonic route [2-4]. In these studies, specific serum antibodies were obtained after immunization by this route. In two of these, carried out in fish [2] and in primates [3], both oral and rectocolonic routes were studied. Higher serum antibody levels were obtained by the rectocolonic route. We found the same result in mice with no detectable antibody level after intra-gastric immunization and a slight increase in antibody level after rectocolonic immunization. These antibodies were mainly IgG and IgM and were probably produced by the general immune system. Thus, the difference observed between rectocolonic and intragastric immunization could be due to different systemic penetration of the antigen. In fact, ovalbumin serum levels are higher after rectocolonic than after intragastric administration (unpublished data). Therefore, the stimulation of the systemic immune system may be greater after rectocolonic than after intragastric administration of ovalbumin.

In the second part of our study, we investigated the effect of a rectocolonic preimmunization with an antigen on the systemic immune response to a subsequent subcutaneous immunization with the same antigen. This has never been previously studied. We found the induction of cellular but not humoral tolerance after this preimmunization. Such a dissociation between cellular and humoral response has already been described in some models of oral or intragastric immunization with ovalbumin $[6,7]$ suggesting different regulatory mechanisms for these two types of tolerance. Suppressive cells induced at the mucosal level [8-10], clonal anergy [11] and soluble factors [12], i.e. fragments of ovalbumin, have been implicated in tolerance induction for cell-mediated immune response to fed antigen. However, it remains to be proven that the same mechanisms are implicated in the cellular tolerance induction that we observed after rectocolonic immunization. On the other hand, the mechanism of humoral tolerance after oral or intragastric administration of a soluble antigen remains poorly understood.

The different systemic immune responses after rectocolonic and intragastric administration of the antigen could reflect variations in the mucosal immune system along the gastrointestinal tract. Recent studies have shown that a greater proportion of intraepithelial lymphocytes were CD8+ and $\gamma \delta+$ in the small bowel than in the colon [13] and that the mucosal lymphocytes had a higher production of different cytokines in the colon than in the small bowel [14]. These variations may correspond to differences in mucosal immunoregulation. However, the different responses after rectocolonic and intragastric immunization could also simply be related to the systemic immune stimulation elicited by these two routes of immunization and to the balance between the mucosal and the systemic stimulation. As shown in the first part of the study, rectocolonic immunization led to higher antiovalbumin antibody level than intragastric immunization. This was possibly related to a greater stimulation of the general immune system. On the other hand, the rectocolonic immunization allows a smaller mucosal contact than the intragastric immunization. Therefore, the induction of systemic humoral tolerance may necessitate a greater mucosal and a smaller general immune stimulation than systemic cellular tolerance.

In conclusion, rectocolonic administration of ovalbumin gives rise to a particular systemic immune response differing from that observed after intragastric administration and characterized by a detectable specific humoral response, an absence of specific humoral tolerance but the induction of a specific cellular tolerance. Further studies to elucidate the cause of this difference are planned.

\section{References}

1 Mowat AM: The regulation of immune responses do dietary protein antigens. Immunol Today 1987;8:93-98.

2 Rombout JW, Block LJ, Lamers CH, Egberts E: Immunization of carp (Cyprinus carpio) with a Vibrio anguillarum bacterin: Indications for a common mucosal immune system. Dev Comp Immunol 1986;10:341-351.

3 Lehner T, Brookes R, Panagiotidi C, Tao L, Klavinskis LS, Walker J, Walker P, Ward R, Hussain L, Gearing AJH, Adams SE, Bergmeier AL: T- and B-cell functions and epitope expression in nonhuman primates immunized with simian immunodeficiency virus antigen by the rectal route. Proc Natl Acad Sci USA 1993;90: 8638-8642. 
Published in : International Archives of Allergy and Immunology (1995), vol. 108, pp. 19-23.

Status : Postprint (Author's version)

4 Forrest BD, Shearman DJ, LaBrooy JT: Specific immune response in human following rectal delivery of live typhoid vaccine. Vaccine 1990;8: 209-212.

5 Haneberg B, Kendall D, Amerongen HM, Ap-ter FM, Kraehenbuhl JP, Neutra MR: Induction of specific immunoglobulin A in the small intestine, colon-rectum, and vagina measured by a new method for collection of secretions from local mucosal surfaces. Infect Immun 1994;62: 15-23.

6 Mowat AM, Ferguson A: Hypersensitivity in the small intestinal mucosa. V Induction of cell-mediated immunity to a dietary antigen. Clin Exp Immunol 1981;43:574-582.

7 Lamont AG, Gordon M, Ferguson A: Oral tolerance in protein-deprived mice. I. Profound antibody tolerance but impaired DTH tolerance after antigen feeding. Immunology 1987;61:333-338.

8 Bland PW, Warren LG: Antigen presentation by epithelial cells of the rat small intestine. II. Selective induction of suppressor T cells Immunology 1986;58:9-14.

9 Richman LK, Chiller JM, Brown WR, Hanson DG, Vaz NM: Enterically induced immunologic tolerance. I. Induction of suppressor T lymphocytes by intragastric administration of soluble proteins. J Immunol 1978; 121:2429-2434.

10 Mattingly JA: Immunologic suppression after oral administration of antigen. EL Activation of suppressor-inducer cells in the Peyer"s patches. Cell Immunol 1984;86:46-52.

11 Whitacre CC, Gienapp IE, Orosz CG, Bitar DM: Oral tolerance in experimental autoimmune encephalomyelitis. II. Evidence for clonal anergy. J Immunol 1991;147:2155-2163.

12 Bruce MG, Ferguson A: The influence of intestinal processing on the immunogenicity and molecular size of absorbed, circulating ovalbumin in mice. Immunology 1986;59:295-300.

13 Beagley KW, Fujihashi K, Lagoo AS, Elson CO: Regional difference in mucosal lymphoid cells of murine small versus large bowel (abstract). Gastroenterology 1992;102:A 593.

14 Sharmanov A, McGhee JR, Beagley K, Fujihashi K, Kiyono H, Lagoo A, Elson CO: Cytokine secretion by intraepithelial and lamina propria lymphocytes from murine small bowel and large bowel (abstract). Gastroenterology 1993; 104:A 780. 